\title{
Lipoic acid synthetase deficiency
}

INSERM

\section{Source}

INSERM. (1999). Orphanet: an online rare disease and orphan drug data base. Lipoic acid synthetase deficiency. ORPHA:401859

Lipoic acid synthetase deficiency is a rare neurometabolic disease characterized by a neonatal onset of seizures (often intractable), muscular hypotonia, feeding difficulties (poor sucking and/or swallowing) and mild to severe psychomotor delay, associated with nonketotic hyperglycinemia typically revealed by biochemical analysis. Respiratory problems (apnea, acute respiratory acidosis), lethargy, hearing loss, microcephaly and spasticity with pyramidal signs may also be associated. 